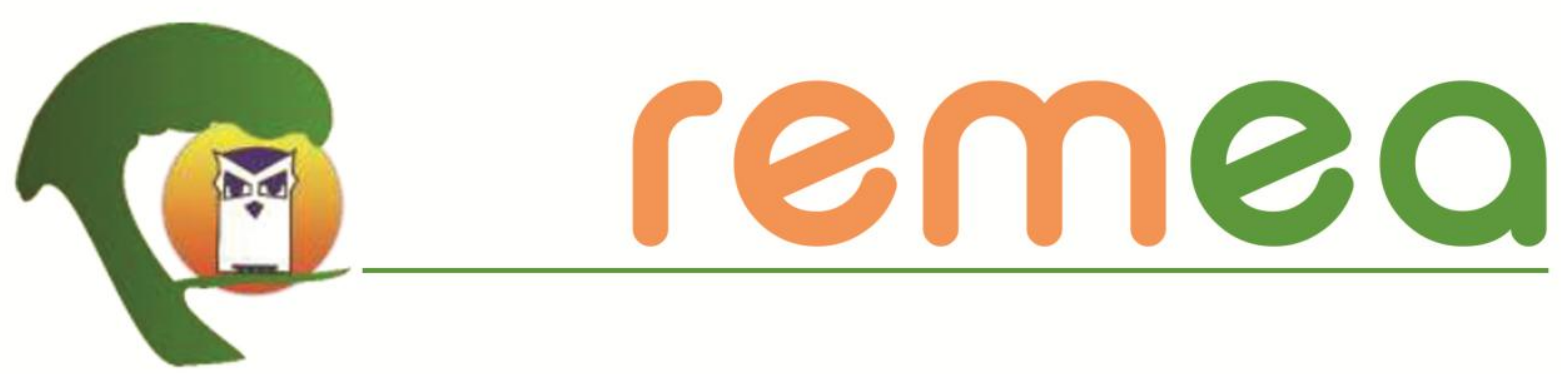

\title{
Onde está o/a educador ambiental na formação docente em Biologia e em Geografia?
}

\author{
Marlécio Maknamara ${ }^{1}$ \\ Universidade Federal da Paraíba - UFPB \\ ORCID: http://orcid.org/0000-0003-0424-5657
}

Resumo: Movimentações sobre possibilidades de relação entre educação ambiental e as disciplinas de Biologia e de Geografia ensejam a hipótese de que práticas de formação docente para tais disciplinas seriam instâncias privilegiadas de constituição de educadores/as ambientais. Este artigo objetiva esboçar conceitos e procedimentos para rastrear indícios da constituição de educadores/as ambientais em narrativas (auto)biográficas de docentes dessas disciplinas, discutindo modos de acessar e de problematizar tais narrativas. Os resultados explicitam limites de conceitos e procedimentos tomados como promissores e os cuidados éticos para esquadrinhar as narrativas (auto)biográficas de docentes. Conclui-se pela necessidade de ampliar formas de atenção desse campo às possibilidades constitutivas de educadores/as ambientais em instâncias, dimensões e questões ainda não exploradas.

Palavras-chave: Educadores/as ambientais. Narrativas (auto)biográficas. Biologia. Geografia.

\section{¿Dónde está el educador ambiental em la formación docente en Biología y Geografía?}

Resumen: Los movimientos sobre posibilidades de relación entre la educación ambiental y las disciplinas de Biología y Geografía dan lugar a la hipótesis de que las prácticas de formación docente para tales disciplinas serían instancias privilegiadas de constitución de educadores ambientales. Este artículo tiene como objetivo esbozar conceptos y procedimientos para rastrear la evidencia de la constitución de los educadores ambientales en las narrativas (auto) biográficas de los docentes en estas disciplinas, discutiendo formas de acceder y problematizar tales narrativas. Los resultados muestran los límites de los conceptos y procedimientos considerados prometedores y el cuidado ético que se toma para escudriñar las narrativas (auto) biográficas de los profesores. Se concluye que existe la necesidad de ampliar las formas de atención en este campo a las posibilidades constitutivas de los educadores ambientales en instancias, dimensiones y temas aún no explorados.

Palabras-clave: Educadores ambientales. Narrativas (auto)biográficas. Biología. Geografía.

\footnotetext{
${ }^{1}$ Doutor em Educação pela UFMG. Professor do Programa de Pós-Graduação em Educação da UFBA e do Centro de Educação da UFPB. Líder do ESCRE(VI)VER: Grupo de Estudos e Pesquisas com Narrativas em Educação/CNPq e Membro Pesquisador do Grupo de Estudos e Pesquisas sobre Currículos e Culturas/CNPq. Email: maknamaravilhas@gmail.com
} 


\begin{abstract}
Movements about possibilities of relationship between environmental education and the disciplines of Biology and Geography give rise to the hypothesis that teacher training practices for such disciplines would be privileged instances of constitution of environmental educators. This article aims to outline concepts and procedures to track evidence of the constitution of environmental educators in (auto)biographical narratives of teachers in these disciplines, discussing ways to access and problematize such narratives. The results show the limits of concepts and procedures taken as promising and the ethical care taken to scrutinize the (auto)biographical narratives of teachers. It is concluded that there is a need to expand forms of attention in this field to the constitutive possibilities of environmental educators in instances, dimensions and issues not yet explored.
\end{abstract}

Keywords: Environmental educators. (Auto)biographical narratives. Biology. Geography.

\title{
Introdução
}

"Construamos juntos as verdades da educação ambiental". Foi com essas palavras que Grün (1995) encerrou um importante estudo sobre produção discursiva da educação ambiental. Entendo que tal convite-desafio não passa apenas pelas formas como temos construído conhecimento em educação ambiental e pelas práticas que temos realizado em nome dela, mas também pela investigação das formas pelas quais um indivíduo é levado a reconhecer-se e/ou ser reconhecido como sujeito da educação ambiental.

Reconhecer-se e/ou ser reconhecido como sujeito de determinado tipo constitui uma das frentes investigativas que temos desenvolvido no ESCRE(VI)VER - Grupo de Estudos e Pesquisas com Narrativas em Educação/UFBA/CNPq. Esse grupo articula pesquisadores/as e estudantes (da graduação à pós-graduação em diferentes IES) empenhados/as em investigar o potencial heurístico das narrativas em educação. Sua agenda de pesquisa inclui problematizações de narrativas em diferentes currículos, instâncias de formação docente e processos de ensinar-aprender. As investigações se valem de referenciais e metodologias variados, no intuito de subsidiar formulações para pesquisas e práticas pedagógicas.

Como Líder do ESCRE(VI)VER, o qual fundei em 2017 e coordeno desde então, desenvolvo e oriento pesquisas interessadas nas formas e forças que disputam significados sobre diferentes sujeitos da educação. São pesquisas que tomam currículos e práticas de formação docente em sua dimensão de acionamento e efeitos de poder que concorrem para processos de subjetivação. Entendo que perseguir tal dimensão é urgente à educação 
ambiental, uma vez que compreender e aprender com as contingências que atravessam histórias de vida, currículos e práticas de formação docentes é central à promoção de futuros sustentáveis. Luitel e Taylor (2019) trazem 19 artigos no sentido dessa premissa.

O interesse por narrativas e pesquisas (auto)biográficas em educação levou-me, em seguida à criação do ESCRE(VI)VER, a produzir texto (MAKNAMARA, 2018) para a coletânea "Educações ambientais possíveis: ecos de Michel Foucault para pensar o presente", a convite da Profa. Dra. Paula Henning, líder do Grupo de Estudos Educação, Cultura, Ambiente e Filosofia/FURG/CNPq. Outro grupo de pesquisa com o qual o ESCRE(VI)VER tem procurado alargar possibilidades em educação ambiental é o RIZOMA/UEFS/CNPq, liderado pelo Prof. Dr. Marco Barzano. Com esse grupo temos também construído coletivamente bancas, eventos e publicações.

Nos primeiros anos de minha formação como pesquisador no campo da EA envolvime intensamente em pesquisas e práticas de formação segundo um referencial crítico (CUNHA, 2007a, 2007b, 2006a, 2006b, 2005a) com vistas às possibilidades de concretização curricular da EA na disciplina escolar de Ciências. Analisar concepções (de meio ambiente, de educação ambiental) em diferentes textos e contextos levou-me a buscar articulações entre subjetividade e crise ambiental, inicialmente no sentido de que diferentes sujeitos da EA se sentissem coautores de vivências restauradoras dos encontros de cada um consigo, com o outro e com o todo (MAKNAMARA e MAHFOUD, 2009). As dinâmicas de meus interesses de pesquisa e de minha trajetória de vida e formação, contudo, têm me possibilitado outras formas de ser e estar no campo da EA (MAKNAMARA, 2011, 2012, 2015, 2018) desde minha imersão no campo das pesquisas pós-críticas em educação. São dessa época minhas primeiras colaborações na avaliação de artigos enviados para os periódicos "Pesquisa em Educação Ambiental" e "RevBEA", publicação no GT 22 da ANPED por ocasião da 34a Reunião Anual da ANPED, publicação na coletânea do Grupo TECENDO - Educação Ambiental e Estudos Culturais/UFSC/CNPq (MAKNAMARA, 2012). 
Tenho aprendido, das teorizações pós-críticas em educação e de suas formas de articular linguagem ${ }^{2}$, conhecimento ${ }^{3}$ e poder $^{4}$, que há disputas para criar verdades em torno do que conta ou não como educação ambiental. Diante da multiplicidade de conceitos, de referenciais e de linguagens para ver e dizer no interior desse campo (REIGOTA, 2012), tenho me inserido nessas disputas entendendo a EA como uma densidade que oscila entre diferentes polos semânticos ao longo do tempo, o que faz dela um ponto de passagem e articulação de relações de poder em torno de questões tidas como ecológicas. Acerca de tais questões, Félix Guattari, um dos referenciais para teorizações pós-críticas em educação no Brasil, identifica "três registros fundamentais da ecologia": meio ambiente, relações sociais e subjetividade humana. Esses são operadores da ecosofia, entendida como uma articulação ético-política problematizadora e esclarecedora dos comprometimentos contemporâneos da subjetividade com sua exterioridade (GUATTARI, 2006).

Ao operar na confluência entre seus três registros, a perspectiva ecosófica não vê respostas à atual crise ecológica sem que haja "uma autêntica revolução política, social e cultural reorientando os objetivos da produção de bens materiais e imateriais" (GUATTARI, 2006, p. 9). Em outras palavras, significa assumir que as relações sociais e as subjetividades também são questões ecológicas (REIGOTA, 1999a). Significa também que os desdobramentos da ecosofia no plano pedagógico podem materializar-se em uma educação ambiental voltada à construção de conhecimentos "sobre temas complexos e desafiadores de nossa época" (REIGOTA, 1999b, p. 83). E se há temas desafiadores e complexos em nossa época, um deles é o da subjetividade.

Há uma "condição problemática da subjetividade na atualidade" (BIRMAN, 2000) que impõe a necessidade de estudos que articulem o educacional, o social, o histórico e o

\footnotetext{
${ }^{2}$ Aquilo que "dá o perfil e a presença das coisas no mero ato de nomeá-las; que dá o ser e a forma às ideias, ao enunciá-las; que dá o ser e a densidade ao sujeito falante, no modo como ele fixa sua posição" (LARROSA, 2002).

${ }^{3}$ Entendido como efeito de uma relação fundamental com regimes de verdade. Por "verdade" Foucault (2007a, p. 13) quer designar o "conjunto das regras segundo as quais se distingue o verdadeiro do falso e se atribui ao verdadeiro efeitos específicos de poder".

${ }^{4}$ Entendido como "uma situação estratégica complexa" em termos de uma "multiplicidade de correlações de força imanentes ao domínio onde se exercem e constitutivas de sua organização" (FOUCAULT, 2001, p. 88-89), poder é aqui pensado em seus aspectos fundamentais de "fluidez, mobilidade, capilaridade e produtividade" e para além de questões jurídicas e de soberania (MAKNAMARA, 2018).
} 
psicológico, que tratem da conexão entre aprendizagens e modos de ser sujeito, que não subestimem os liames entre processos de subjetivação e as variadas instâncias do pedagógico (MAKNAMARA, 2020). No campo da EA, um trabalho pioneiro de atenção a tal problemática e de ampliação da ecosofia esboçada por Guattari, é "Ecologistas" (REIGOTA, 1999a). Trata-se de um constructo de narrativas ficcionais "misturando as informações, acontecimentos, relatos e pessoas", narrativas "das 'experiências', das 'vivências', tudo isso entre aspas, das pessoas que se identificam como ecologistas" (REIGOTA, 2021, p. 129). Também foram trabalhadas por Reigota e Prado (2008) narrativas de si em que extensionistas e docentes priorizaram a temática ambiental. Esses escritos foram chamados de "bio:grafias" e "não são nem podem ser considerados narrativas autobiográficas" (REIGOTA e PRADO, 2008, p. 128). Mas... e quanto a indivíduos que, embora não sejam definidos como ecologistas, são considerados educadores/as ambientais "natos", tais como docentes de Biologia e de Geografia? O que faria ser educador/a ambiental em narrativas (auto)biográficas desses docentes?

Por mais que se insista que a educação ambiental não é propriedade de nenhuma disciplina, com bastante facilidade ainda circula a ideia de que Biologia e Geografia seriam seus "habitats naturais". Teses, dissertações, artigos, sites e uma infinidade de outros artefatos dirigidos a docentes prosseguem sugerindo, argumentando, demandando que essa relação seria imediata, inequívoca, intrínseca ou até mesmo natural. Os efeitos desse imaginário fazem-se sentir: em formas de entrada e de responsabilização da temática ambiental nos currículos escolares (KAWASAKI e CARVALHO, 2009); na superioridade de conteúdo voltado à temática ambiental em livros de biologia e de geografia relativamente às demais disciplinas (SILVA e SANTOS, 2019); em desconsideração de aspectos dessa temática, desde a formação inicial, como possibilidade didática em outras disciplinas (SILVA e CARVALHO, 2012). Considerar toda a movimentação em torno dessas possibilidades de relações entre EA e Biologia e Geografia (áreas de minha formação inicial), enseja a hipótese de que práticas de pesquisa-formação docente para essas disciplinas escolares seriam instâncias privilegiadas de ver e de dizer a constituição de educadores/as ambientais. Será? 
Interessado nos rastros de indivíduos passíveis de se reconhecerem e/ou de serem reconhecidos como sujeitos educadores/as ambientais, assumo o território existencial do "dissenso como potência criadora" na EA, no sentido de uma disposição para "pensar, provocar, ranger, rachar as verdades estabelecidas, os modos comuns e a sua reprodução" (HENNING e SILVA, 2018, p. 158). Para procurar responder à questão supracitada, intento partir de um mapeamento de pesquisas (auto)biográficas de docentes de Biologia e de Geografia, em um projeto de pesquisa financiado por Chamada Interna da Universidade Federal da Paraíba (de onde sou professor).

Apresentei os primeiros desafios e resultados desse projeto em Maknamara (2021a). Aqui, eles são retomados e ampliados, desdobrados em conceitos e procedimentos metodológicos tomados como promissores e em uma discussão sobre cuidados éticos para esquadrinhar narrativas (auto)biográficas de docentes. Escolher e articular conceitos, prospectar e criar procedimentos metodológicos promissores e compatíveis com um objeto de estudo, assim como estimar e problematizar possíveis cuidados investigativos constituem, todos eles, movimentos investigativos e os primeiros resultados de uma pesquisa pós-crítica em educação, sobretudo por se tratar de pesquisas que assumem os construcionismos de suas realidades e as contingencialidades de suas metodologias.

No Brasil, as pesquisas (auto)biográficas se consolidaram por possibilitar a ressignificação de experiências e de marcas constitutivas de sujeitos em nível individual e coletivo (SOUZA, 2014). Focadas em reflexividades, resgates de trajetórias, atribuições de sentidos, ressignificações de experiências, novas capacidades, conquistas, aprendizagens emancipatórias, formas e reposicionamentos docentes, as pesquisas (auto)biográficas têm feito grandes promessas de contrapartidas à formação de professores. Por isso, entendo-as como material empírico privilegiado para rastrear indícios da constituição de educadores/as ambientais em narrativas de pesquisa-formação docente em Biologia e Geografia. Mas com que conceitos e procedimentos seria possível rastrear indícios da constituição de educadores/as ambientais em narrativas de pesquisa-formação docente?

\section{Lastro conceitual, horizontes teórico-metodológicos e procedimentos a adotar}


A investigação aqui em tela tem inspiração nas teorias pós-críticas em educação. As teorizações pós-críticas em educação no Brasil ganham espaço quando, nos idos da década de 1990, problematizam-se as transformações na economia, na política e na cultura para focalizar reestruturações que o neoliberalismo, movimentos sociais e viradas epistemológicas vinham provocando na educação. "Colisão entre o velho e o novo", "dissoluções de fronteiras", "introdução de mecanismos de mercado na educação", "estado de revolução cultural", "ambientes de profusão e saturação de imagens", "estímulos ao consumo cultural", "revoluções teóricas e epistemológicas" - alguns dos termos usados à época para falar das transformações que impactavam a sociedade e pressionavam reestruturações na escola, no currículo e no trabalho docente - ajudaram a inteligir "uma virada epistemológica radical" que estava a redimensionar princípios, métodos e procedimentos da teorização social e educacional (SILVA, 1997).

Tais redimensionamentos, tributários de abordagens teóricas como o pósestruturalismo, pós-modernismo, pós-colonialismo, pós-gênero, pós-feminismo, multiculturalismo, estudos culturais, estudos queer, filosofias da diferença, estudos étnicoraciais (PARAÍSO, 2021), passam a ser sintetizados e expressos nas chamadas teorias póscríticas em educação. Em suas sínteses, as teorias pós-críticas em educação partem de pressupostos variados: visão perspectivista do conhecimento; verdade como composição; caráter produtivo da linguagem e das relações de poder; questionamento do sujeito transcendental, universal, autocentrado e indivisível; contingencialidade e heterogeneidade na formação da subjetividade; privilégio da diferença e da multiplicidade em detrimento da identidade e da mesmidade (CORAZZA e SILVA, 2003; PARAÍSO, 2021). Desde então, se por um lado as teorias pós-críticas significam crítica e recusa a formas canônicas de conhecimento, por outro lado implicam em acolhida, experimentação e legitimação de formas alternativas que assumem e privilegiam o dissidente, o local, o parcial e o provisório nos processos de conhecer em educação.

Ao considerar o objeto e as questões de pesquisa aqui em tela, os procedimentos metodológicos a adotar tomam, das teorias pós-críticas, os estudos foucaultianos. Tais procedimentos compreenderão esquadrinhar as narrativas (auto)biográficas de docentes de 
Biologia e de Geografia mediante problematização das experiências de si nelas contidas. O foco de uma problematização de inspiração foucaultiana é cercar e apreender "o conjunto das práticas discursivas ou não-discursivas que faz alguma coisa entrar no jogo do verdadeiro e do falso e o constitui como objeto para o pensamento (seja sob a forma de reflexão moral, do conhecimento científico, da análise política etc.)" (FOUCAULT, 2004, p. 242). Nesse sentido, fazer problematização é engendrar certa atitude de pesquisa. Que atitude seria essa? Uma atitude crítica diante das coisas do mundo, uma atitude crítica que reverbera nas delimitações de nossos objetos e trajetos de pesquisa e (de)formação.

Mas o que seria "crítica", afinal? "O movimento pelo qual o sujeito se dá o direito de interrogar a verdade sobre seus efeitos de poder e o poder sobre seus discursos de verdade. Bem, então!: crítica será a arte da insubordinação voluntária, da indocilidade refletida" (FOUCAULT, 1997, p. 32). Tal crítica "não consiste em dizer que as coisas não estão bem como estão. Ela consiste em ver sobre que tipos de evidências, de familiaridades, de modos de pensamento adquiridos e não refletidos repousam as práticas que aceitamos" (FOUCAULT, 2010, p. 356). Vê-se, portanto, que se faz problematização ao se fazer um tipo particular de crítica: uma crítica pautada no esquadrinhamento do que é dado como banal, como autoevidente ou como aceitável, baseado em tipologias, descrições e composições de pensamentos, de certezas e de mobilizações de desejos e práticas.

Na esteira dessa discussão, outro conceito importante para esta empreitada trata da "experiência de si", entendida como "aquilo a respeito do qual o sujeito se oferece seu próprio ser quando se observa, se decifra, se interpreta, se descreve, se julga, se narra, se domina, quando faz determinadas coisas consigo mesmo" (LARROSA, 1999, p. 43). Entendo experiência de si como uma forma de produção de subjetividades. Na confluência entre meio ambiente e relações sociais, subjetividade é um operador da "perspectiva ecosófica" cujo aprofundamento constitui um desafio à práxis ecologista (REIGOTA, 1999) e focalizá-la em sua constituição nos ajudaria a ver e dizer sujeitos da EA. A problematização dessas experiências de si possibilitaria rastrear indícios da constituição de educadores/as ambientais porque dá visibilidade às posições de sujeito em jogo nas narrativas (auto)biográficas, entendidas tais posições como variáveis/funções de enunciados "que 
literalmente constroem o sujeito, na mesma operação em que the atribuem um lugar discursivo" (LARROSA, 1999, p. 66).

Toda essa atitude investigativa passa também por uma recusa a metanarrativas em EA. Metanarrativa pode ser entendida como "qualquer sistema teórico ou filosófico com pretensões de fornecer descrições ou explicações abrangentes e totalizantes do mundo ou da vida social" (SILVA, 2000, p. 78); metanarrativa entendida como uma narrativa cujas eficácia retórica e vontade de dominância, pautadas em ambições grandiloquentes, pretensões universalizantes e projeções utópicas, ocultam tanto suas cumplicidades na constituição daquilo de que falam quanto seu fechamento de possibilidades de leitura. Essa recusa a metanarrativas implica em evitar situar a EA em termos ortodoxos, normativos e universalizantes, o que leva à possibilidade de reconhecer educadores/as ambientais, nas pesquisas (auto)biográficas de docentes, em uma multiplicidade de posições passíveis de abrigo sob definições tão abertas quanto generosas de EA, como quando ela é entendida como conjunto de práticas pedagógicas que "interferem, influenciam e modificam, mesmo que por dimensões temporais limitadas, a vida cotidiana. Elas modificam as relações sociais e afetivas e também as relações com o que as pessoas consideram meio ambiente" (GODOY, GUIMARÃES e REIGOTA, 2010, p. 180). Mas por onde começar a buscar tal multiplicidade?

A metodologia adotada contemplará a leitura, esquadrinhamento e problematização de narrativas (auto)biográficas nas pesquisas mapeadas conforme descrito anteriormente, visando a compreender como seus discursos operam em processos de subjetivação docente tanto em Biologia quanto em Geografia. Com base em trabalhos de Michel Foucault, esse tipo particular de discurso será tomado como elemento de subjetivação de indivíduos, especificamente docentes de Biologia e de Geografia. Para tanto, adotarei como abordagem metodológica a genealogia - tal como utilizada por Foucault, o que implica em "apreender as perspectivas, desdobrar as dispersões e as diferenças, deixar a cada coisa sua medida e sua intensidade" (FOUCAULT, 2007b, p. 29), constitui ferramenta fundamental ao propósito de analisar a produtividade dos discursos das narrativas (auto)biográficas sobre a fabricação de docentes de Biologia e de Geografia. 
A abordagem genealógica foucaultiana liga-se às análises das contingências que nos fazem ser o que somos, evidenciando as conexões entre saber e poder em cujo interior se produz o sujeito. Nesse sentido, os efeitos de poder atrelados ao discursivo se configuram como questões de análise no que diz respeito a "distinguir os acontecimentos, diferenciar as redes e os níveis a que pertencem" (FOUCAULT, 2007a, p. 5). Operar com tal perspectiva metodológica significa optar por uma dimensão analítica "localizada entre os níveis singular e universal da experiência subjetiva, que visa detectar aqueles elementos comuns a alguns sujeitos, mas não necessariamente inerentes a todos os seres humanos" (SIBILIA, 2008, p. 16). Significa tomar narrativas (auto)biográficas como textos em cuja discursividade vê-se o que Rose (2001b) chamou de "vozes das autoridades": vozes carreadoras de esperança ou de medo, uma forma peculiar de ligar objetos a valores e sentidos, certas técnicas de pensamento e ação.

Como vozes de autoridade de docentes sobre si mesmos/as, tais narrativas possibilitam investigar os efeitos de verdade e as tecnologias instituídos pelos discursos que as constituem, os quais terminam por moldar e orientar a conduta de docentes, ou seja, concorrer para processos de subjetivação docente. Esse efeito habilitador e inovador do (auto)biográfico é reconhecido para ambas as disciplinas: Moss (2001, p. 9, tradução minha) enfatiza que é "autobiograficamente" que o sujeito tem sido redefinido e remapeado em Geografia; em Biologia, tais narrativas fazem um/a docente situá-las como "modificadoras de todo o meu paradigma como pessoa, como professor e como formador de professores" (TAYLOR e MEDINA, 2019, p. 54, tradução minha). Pretendo, dessa forma, contribuir com a problematização de inúmeros discursos que têm engendrado modos de ser e estar na docência em Biologia e em Geografia e, assim, têm a aproximado ou não da EA.

No que diz respeito a possibilidades de fontes para a pesquisa aqui em tela, os mais amplos e detalhados levantamentos de pesquisas brasileiras, tanto em ensino de Biologia quanto em ensino de Geografia, focalizam somente teses e dissertações e afirmam que as pesquisas (auto)biográficas têm sido pouco frequentes na produção acadêmica nacional em ensino de Geografia e em ensino de Biologia (MAKNAMARA, 2021b). Contudo, ainda que em ambas as áreas os levantamentos mais recentes tendam a confirmar essa informação para 
dissertações e teses, deixam em aberto o que podemos saber, com acurácia, sobre pesquisas (auto)biográficas de docentes de Biologia e de Geografia no Brasil. Nesse sentido, é possível partir de um mapeamento que recorra a pesquisas (auto)biográficas de docentes de Biologia e de Geografia publicadas em seus respectivos eventos expressivos de área Encontro Nacional de Ensino de Biologia (ENEBIO) e Encontro Nacional de Ensino de Geografia (ENPEG) -, além do Congresso Internacional de Pesquisa (Auto)Biográfica (CIPA). Mais quais as implicações éticas envolvidas nessa possibilidade de escolha?

\section{Valores, questões e procedimentos éticos para acessar e problematizar o empírico}

Além da necessidade de clareza conceitual, problematizar pesquisas (auto)biográficas de docentes de Biologia e de Geografia no sentido da constituição de educadores/as ambientais traz desafios éticos quanto às fontes orais e escritas a escolher como material empírico. Ao tomar as narrativas (auto)biográficas como práticas discursivas atravessadas por relações de poder que concorrem para a subjetivação de docentes de Biologia e de Geografia, inevitavelmente questões de fundo ético vêm à tona. No que interessa à investigação aqui proposta, é sabido que o poder deixa marcas de seu exercício e que essas marcas se fazem presentes em narrativas (auto)biográficas. Mas como, sem comprometer-se eticamente, encontrá-las e esquadrinhá-las nas escritas que docentes fazem de si?

Ao concordar com a recomendação de que pesquisadores/as da área de Educação explicitem as questões éticas em seus documentos de pesquisa (AMORIM et al., 2019), passarei a explicitar pontos disparadores de reflexão e de vigilância sobre questões éticas que atravessam a formulação e execução da pesquisa aqui em cena.

- Quanto aos valores norteadores da análise:

Partirei da compreensão de que a pesquisa e a escrita pós-crítica em educação é parcial e subjetiva (MAKNAMARA, 2021b). Nesse quadro de análises, tomarei as pesquisas (auto)biográficas como elementos centrais na "economia política" de verdades sobre a docência, assumindo também minha posição de pesquisador nessa disputa por significação. 
Desde Maknamara (2011), tenho entendido que operar com esse tipo de análise, além de valorizar como discursos configuram-se em meio a relações de poder e concorrem para processos de subjetivação, o que não é pouco, implica em inserir-se em jogos de produção do verdadeiro. Sem negar a produtividade das pesquisas (auto)biográficas do ponto de vista educacional, social e político, mas no intuito de apontar outras possibilidades analíticas e potencialidades formativas, desejo evidenciar os aspectos reguladores do (auto)biográfico sobre a docência nas disciplinas escolares aqui focalizadas, no sentido de aproximação a uma experiência da educação ambiental.

- Questões éticas envolvidas na coleta de dados:

De posse de toda a produção que será mapeada - pesquisas (auto)biográficas de docentes de Biologia e de Geografia, como já dito -, cada respectiva autoria de trabalho mapeado será contatada por e-mail, que Ihes esclarecerá e convidará a participar da pesquisa. Terá seu texto considerado para análise somente a pessoa que, dentre esse conjunto de autorias, sentir-se esclarecida e aceitar contribuir autorizando a análise de seu texto. O esclarecimento incluirá saber também que, a depender do volume de texto mapeado, do número de autorizações de análise e do tempo disponível para a pesquisa, poderei optar por incluir outras produções das mesmas autorias já mencionadas, desde que inspiradas nos métodos (auto)biográficos. A pesquisa terminará quando de posse das informações desejadas: em não havendo previsão de riscos significativos, não há previsão de suspensão da pesquisa.

- Questões éticas na explicitação da abrangência, importância e benefícios da pesquisa:

Explicitarei, a cada autoria de trabalho que resultar do mapeamento de produção, as alternativas de contribuição com a pesquisa: estarei mapeando e produzindo informações no âmbito de um projeto de pesquisa específico; cada autoria de trabalho mapeado terá o direito de não contribuir com o estudo; os textos resultantes do mapeamento, mesmo oriundos de eventos de domínio público, não serão analisados sem o devido esclarecimento e aquiescência da parte de sua autoria; se a autoria não autorizar análise de seu texto mapeado, isto não interferirá em sua vida profissional; a qualquer momento, qualquer 
pessoa poderá declinar da contribuição com a pesquisa sem lhe trazer qualquer penalidade ou prejuízo.

Os registros dos textos mapeados serão utilizados apenas para produção de resultados da pesquisa. O objetivo e a importância do estudo serão esclarecidos em termos da problematização dos inúmeros discursos que têm engendrado modos de ser e estar na docência em Biologia e Geografia no sentido de identificar possibilidades de uma experiência da educação ambiental: será esclarecido que o projeto de pesquisa dará, especificamente, relevância à produtividade de discursos na constituição de subjetividades, o que implica em reconhecer que narrativas (auto)biográficas atuam na elaboração da docência, mais que simplesmente narrá-la. Explicitarei, a cada autoria de trabalho mapeado, que meu horizonte maior é contribuir, nas especificidades da presente pesquisa, com a identificação de desafios aos cenários de atuação docente nas referidas disciplinas e possibilidades de articulação com o campo da EA.

- Questões éticas envolvidas nas ambições e indagações da pesquisa:

Procurarei instalar-me no espaço-entre, no meio daquilo que as escritas de si oferecem e abrem como possibilidade, ou seja, procurarei apreender o discurso em seu poder de afirmação, seu poder de constituir "domínios de objetos, a propósito dos quais se poderia afirmar ou negar proposições verdadeiras ou falsas" (FOUCAULT, 1996, p. 70). material empírico será lido no sentido de deixar as narrativas em questão tão somente falarem. Significa que sua leitura não será orientada para a captação de aspectos formais e lógicos dos textos, nem para a busca de significados reais que seriam desocultados mediante interpretação, tampouco para julgamentos de cunho moral.

A leitura será feita no sentido de captar as múltiplas possibilidades de um discurso em termos das coisas ditas (MAKNAMARA, 2021b), entendendo que o material empírico dá a ver as sutilezas de poder enquanto aparentemente apenas testemunha ditos e feitos de quem escreve sobre si. Favoráveis ou não, os resultados serão publicados. Ainda que os textos do mapeamento advenham de eventos públicos e sejam de natureza (auto)biográfica, 
não divulgarei, sem consentimento, nenhum dado de pesquisa no qual a autoria dos textos mapeados seja identificada por si ou por outrem.

- Questões éticas que atravessarão a análise do material empírico:

Buscarei explorar e dar parcialmente conta das posições de sujeito tornadas visíveis e dizíveis nessas escritas de si. Embora não se trate de uma empreitada cartográfica (ROLNIK, 1989), deixar-me-ei afetar pelo material que terei em mãos e manter-me aberto ao que dele poderá emergir. Ofereço-me a captar sensações e surpresas provocadas pelos encontros com os universos existenciais que esse material sugerirá.

Estarei atento àquilo que, do contato com tal material, movimentará meu pensamento como educador ambiental. Seguirei as pistas deixadas por combinações particulares de fragmentos das escritas de si (extraídas das narrativas de cada pesquisador/a a que tiver acesso) e das composições que delas vierem a emergir. Tais fragmentos serão escolhidos e dispostos em uma série de excertos mutuamente significativos, de modo a tornar visíveis discursos e posições de sujeito emergentes das associações feitas por mim.

- Questões e dilemas do pesquisador na produção e redação dos resultados da pesquisa:

Estarei permanentemente atento ao fato de que a construção dos resultados indicará uma leitura particular das narrativas dos docentes, representará minha capacidade e meu esforço de manusear o material (escrito com outros propósitos, sob outras circunstâncias), de acessar os elementos que eu procurarei e de Ihes conferir inteligibilidade particular. Também considerarei e ressaltarei que se trata de uma leitura muito própria também porque, inevitavelmente (embora não apenas), marcada pelo meu lugar de enunciação, pelos discursos que me atravessam e que me constituem sujeito em múltiplas posições.

Assim, na leitura e na análise das narrativas, não me posicionarei como pesquisador pretensamente imparcial e livre de constrangimentos para analisar um material tão rico e belo; procurarei posicionar-me como, se não imerso nos mesmos problemas e interesses postos nas narrativas, pelo menos como alguém empático a seus temas e questões. Com isso, operacionalizarei a pesquisa e a escrita pós-críticas como inscrição, deixando claro por meio de meus textos como me apresento, como me coloco no mundo e como gostaria que 
meus objetos fossem apresentados em suas conexões com outros objetos e conceitos (MAKNAMARA, 2021).

\section{Considerações finais}

Rastrear indícios da constituição de educadores/as ambientais em narrativas de pesquisa-formação docente em Biologia e Geografia enseja a necessidade de discutir tanto os limites dos conceitos e procedimentos tomados como promissores (ou não) para uma aproximação ao objeto de estudo quanto os cuidados éticos a serem tomados para fazer os sujeitos do material empírico efetivamente participarem da pesquisa, discussão que procurei aqui iniciar.

Narrativas (auto)biográficas de educadores ambientais e de outros sujeitos reconhecidamente "ecológicos" (CARVALHO, 2004) deram importantes informações sobre saberes, práticas e projetos políticos em disputa no campo da EA (CARVALHO, 2002; REIGOTA e PRADO, 2008). Acompanhar trajetórias e práticas em narrativas de docentes que "incorporam a educação ambiental como filosofia e proposta político-pedagógica" também tem possibilitado aprender com seus "movimentos no cotidiano escolar na direção dos princípios básicos que nos são tão caros" (REIGOTA, 2017, p. 262).

Ao serem analisadas demandas e agendas recentes de pesquisa em educação ambiental defendeu-se que "procurar compreender os processos de constituição do que somos e de onde estamos" possibilita "vislumbrar possibilidades de nos tornarmos diferentes, de produzirmos algo também diferente, e de problematizarmos os slogans e as crenças já enraizados em nossas histórias" (CARVALHO, 2016, p. 149). Contudo, de 1981 a 2012, é reduzido tanto o número de teses e dissertações em EA que se valem metodologicamente dessas narrativas quanto o número daquelas que se valem da perspectiva epistemológica valorizada no presente projeto de pesquisa (CARVALHO et al., 2018).

Assim, se a EA vive tempos em que nossos compromissos de pesquisa precisam ser compromissos com a vida, também no sentido "de investigá-la, de produzir múltiplos, diversos e criativos sentidos" (CARVALHO, 2013, p. 46); se vivemos tempos em que efeitos 
de pulsões destrutivas ameaçam as vidas de educadores e educadoras ambientais com produções de medo, desalento, preocupação, tristeza e decepção (CARVALHO, 2020); se ampliações das formas de atuação no campo da EA tornam-se cada vez mais urgentes e necessárias (REIGOTA, 2012); se a EA “pode ser diferentes coisas e nisso está sua potência" (HENNING, 2020, p. 208); então, é fundamental retomar "mitos de origem, vias de acesso e ritos de entrada" (CARVALHO, 2002) para ampliar formas de atenção desse campo às possibilidades constitutivas de educadores/as ambientais em instâncias, dimensões e questões ainda não exploradas.

Ao apontar para conexões analíticas entre educação ambiental, narrativas (auto)biográficas e docência em Biologia e em Geografia, interessado nos rastros de indivíduos passíveis de se reconhecerem e/ou de serem reconhecidos como educadores/as ambientais, assumo o território existencial do "dissenso como potência criadora" na EA, no sentido de uma disposição para "pensar, provocar, ranger, rachar as verdades estabelecidas, os modos comuns e a sua reprodução" (HENNING e SILVA, 2018, p. 158). Sendo instâncias privilegiadas quanto a modos de ver e dizer a docência, pesquisas (auto)biográficas de docentes de Biologia e de Geografia são tão importantes quanto urgentes para a EA, já que constituem fontes para investigações em que as narrativas memorialísticas nessas pesquisas, entendidas como um jogo de significações entre a materialidade, as potencialidades e a ficcionalidade de fatos do vivido, mais do que tão somente "contar", terminam por produzir a docência e possibilidades de uma experiência da educação ambiental.

\section{Referências}

AMORIM, Antonio C. R.; FERRAÇO, Carlos E.; CARVALHO, Isabel C. M.; MAINARDES, Jefferson; NUNES, João B. C. Ética e pesquisa em Educação: documento introdutório. In: Anped. Comissão de Ética. (Org.). Ética e pesquisa em Educação - v. 1. Rio de Janeiro: Anped, 2019, p. 07-17.

BIRMAN, Joel. Subjetividade, contemporaneidade e educação. In: CANDAU, Vera M. (org.). Cultura, linguagem e subjetividade no ensinar e aprender. Rio: DP\&A, 2000, p. 11-28.

CARVALHO, Isabel C. M. A pesquisa em educação ambiental: perspectivas e enfrentamentos. Revista Pesquisa em Educação Ambiental, v. 15, n. 1, p. 39-50, 2020. 
CARVALHO, Isabel C. M. Educação Ambiental: a formação do sujeito ecológico. São Paulo: Cortez, 2004. 256 p.

CARVALHO, Isabel C. M. A invenção ecológica: narrativas e trajetórias da educação ambiental no Brasil. 2. ed. Porto Alegre: EdUFRGS, 2002. 229 p.

CARVALHO, Luiz M. de; MEGID NETO, Jorge; KAWASAKI, Clarice S.; BONOTTO, Dalva M. B.; AMARAL, Ivan A. do; FERNANDES, José A. B.; SANTANA, Luiz C.; CARVALHO, Maria B. S. S.; CAVALARI, Rosa M. F. Environmental education research in Brazil: some highlights from theses and dissertations. Environmental Education Research, v. 24, n. 10, p. 1447-1463, 2018.

CARVALHO, Luiz M. de. Demandas e agendas da pesquisa em educação ambiental no Brasil: sentidos construídos a partir dos relatos dos grupos de discussão de pesquisa em educação ambiental (GDPs -EPEAs). Pesquisa em Educação Ambiental, vol.11, n.2, p. 146-167, 2016.

CARVALHO, Luiz M. de. Pesquisa em Educação Ambiental: compromisso com a vida. Ciências Humanas e Sociais em Revista, v. 35, p. 35-47, 2013.

CARVALHO, Luiz M. de.; TOMAZELLO, Maria G. C.; OLIVEIRA, Haydée T. Pesquisa em educação ambiental: panorama da produção brasileira e alguns de seus dilemas. Cadernos CEDES, v. 29, n. 77, p. 13-27, 2009.

CORAZZA, Sandra; SILVA, Tomaz Tadeu da. Composições. Belo Horizonte: Autêntica, 2003. $132 \mathrm{p}$.

CUNHA, Marlécio M. da S. Diagnóstico ambiental e formação de educadores ambientais: uma experiência de articulação entre ensino e pesquisa. Revista Brasileira de Educação Ambiental, v. 2, p. 77-87, 2007a.

CUNHA, Marlécio M. da S. A temática ambiental na educação científica segundo as políticas curriculares oficiais brasileiras. Linhas Críticas, v. 13, p. 219-234, 2007b.

CUNHA, Marlécio M. da S. O caos conceitual-metodológico na Educação Ambiental e algumas possíveis origens de seus equívocos. Ambiente \& Educação (FURG), v. 11, p. 75-85, 2006a.

CUNHA, Marlécio M. da S. Paz e Educação Ambiental: desafios à Educação no Sertão Alagoano. Interagir (UERJ), v. 9, p. 159-164, 2006b. 
CUNHA, Marlécio M. da S. A prática pedagógica de professores de Ciências e suas relações com a Educação Ambiental. 2005a. 114 f. Dissertação (Mestrado) - Universidade Federal da Paraíba, Centro de Educação, 2005a.

CUNHA, Marlécio. Navegando em problemas, transformando a comunidade: diagnóstico ambiental e formação de educadores ambientais pela e para a Extensão. In: Ana Inês Sousa. (Org.). Navegar é preciso... transformar é possível. Rio de Janeiro: UFRJ, 2005b, p. 388-395.

FOUCAULT, Michel. É importante pensar?. In: MOTTA, M. B. (Org.). Repensar a política. Rio de Janeiro: Forense Universitária, 2010, p. 354-358.

FOUCAULT, Michel. Verdade e poder. In: MACHADO, Roberto (Org.). Microfísica do Poder. 23. ed. Rio de Janeiro: Graal, 2007a, p. 01-14.

FOUCAULT, Michel. Nietzsche, a genealogia e a história. In: MACHADO, Roberto (Org.). Microfísica do Poder. 23. ed. Rio de Janeiro: Graal, 2007b, p. 15-37.

FOUCAULT, Michel. O cuidado com a verdade. In: MOTTA, M. B. (Org.). Ética, sexualidade, política. Rio de Janeiro: Forense Universitária, 2004, p. 240-251.

FOUCAULT, Michel. História da Sexualidade I. 14. ed. Rio de Janeiro: Graal, 2001. 152 p.

FOUCAULT, Michel. What is critique?. In: FOUCAULT, M. The politics of truth. Los Angeles: Semiotext(e), p. 23-82, 1997.

FOUCAULT, Michel. A ordem do discurso. 3. ed. São Paulo: Loyola, 1996. 79 p.

GODOY, Ana; GUIMARÃES, Leandro Belinaso.; REIGOTA, Marcos. Educação ambiental: um prólogo e três episódios de (re)existência. In: BERINO, A.; SOARES, C. (Orgs.). Educação e imagens: instituições escolares, mídias e contemporaneidade. Petrópolis - Rio de Janeiro: DPetAlli - FAPERJ, 2010, p. 165-182.

GRÜN, Mauro. A produção discursiva sobre educação ambiental: terrorismo, arcaísmo e transcendentalismo. In: VEIGA NETO, Alfredo (Org.). Crítica pós-estruturalista e educação. Porto Alegre: Editora Sulina, 1995, p. 159-184.

GUATTARI, Félix. As três ecologias. 17. ed. Campinas: Papirus, 2006. 56 p.

HENNING, Paula C. Educação ambiental e filosofia da ciência: ressonâncias foucaultianas. In: CHAVES, Silvia; AMORIM, Antonio C.; GASTAL, Maria; BASTOS, Sandra; FERREIRA, Márcia Serra (Orgs.). Vidas que ensinam o ensino da vida. São Paulo: LF, 2020, p. 191-211. 
HENNING, Paula C.; SILVA, Gisele R. Rastros da educação ambiental: o dissenso como potência criadora. In: HENNING, P. C.; MUTZ, A. S. C.; VIEIRA, V. T. (Orgs.). Educações ambientais possíveis: ecos de Michel Foucault para pensar o presente. Curitiba: Appris, 2018, p. 151-162.

KAWASAKI, Clarice S.; CARVALHO, Luiz M. de. Tendências da Pesquisa em Educação Ambiental. Educação em Revista, v. 25, n. 3, p. 143-157, 2009.

LARROSA, Jorge. Literatura, experiência e formação. In: COSTA, Marisa V. (Org.). Caminhos investigativos: novos olhares na pesquisa em educação. Porto Alegre: Mediação, 2002. p. 133-160.

LARROSA, Jorge. Tecnologias do eu e educação. In: SILVA, T. T. O sujeito da educação: estudos foucaultianos. 3. ed. Petrópolis: Vozes, 1999, p. 35-86.

LUITEL, Bal C.; TAYLOR, Peter C. (Orgs.). Research as transformative learning for sustainable futures: glocal voices and visions. London: Brill, 2019. 332 p.

MAKNAMARA, Marlécio. Educadores/as ambientais em pesquisas (auto)biográficas de docentes de biologia e de geografia: um objeto em construção. In: 40a Reunião Nacional da ANPEd, Belém, 2021a.

MAKNAMARA, Marlécio. Afinidades e afinações pós-críticas em torno de currículos de gosto duvidoso In: PARAÍSO, M. e MEYER, D. E. E. (Orgs.). Metodologias de pesquisas pós-críticas em educação. 3. ed. Belo Horizonte: Mazza, 2021b, p. 155-174.

MAKNAMARA, Marlécio. Quando artefatos culturais fazem-se currículo e produzem sujeitos. Reflexão e Ação, Santa Cruz do Sul, v. 27, p. 58-72, 2020.

MAKNAMARA, Marlécio. O que faz um educador ambiental?. In: HENNING, Paula C.; MUTZ, Andreza S. C.; VIEIRA, Virgínia T. (Orgs.). Educações ambientais possíveis: ecos de Michel Foucault para pensar o presente. Curitiba: Appris, 2018, v. 1, p. 163-178.

MAKNAMARA, Marlécio. Natureza e desenhos animados: conexões com a formação docente em ciências. Alexandria (UFSC). Florianópolis, v.8, p.75 - 87, 2015.

MAKNAMARA, Marlécio. "NEM PARECE O NORDESTE": (des)serviços da educação ambiental ao dispositivo pedagógico da nordestinidade. In: PREVE, Ana M.; GUIMARÃES, Leandro B.; BARCELOS, Valdo; LOCATELLI, Julia S. (Orgs.). Ecologias inventivas: conversas sobre educação. Santa Cruz do Sul-RS : EDUNISC, 2012, p. 199-212. 
MAKNAMARA, Marlécio. Currículo, gênero e nordestinidade: o que ensina o forró eletrônico? 2011. 151f. Tese (doutorado) - Faculdade de Educação, Universidade Federal de Minas Gerais, Belo Horizonte, 2011.

MAKNAMARA, Marlécio; MAHFOUD, Miguel. Subjetividade, crise e educação ambiental. Revista Mal-Estar e Subjetividade, v. 9, p. 251-275, 2009.

MOSS, Pamela. Writing one's life. In: MOSS, Pamela (Org.). Placing autobiography in geography. Syracuse, New York: Syracuse University Press, 2001, p. 1-21.

PARAÍSO, Marlucy. Metodologias de pesquisas pós-críticas em educação e currículo: trajetórias, pressupostos, procedimentos e estratégias analíticas. In: PARAÍSO, M. e MEYER, D. E. E. (Orgs.). Metodologias de pesquisas pós-críticas em educação. 3. ed. Belo Horizonte: Mazza, 2021, p. 25-47.

REIGOTA, Marcos. Entrevista a Leandro Belinaso e Davi de Codes. In: BELINASO, Leandro; CODES, DAVI de. Na pele do mundo: educações ambientais. Florianópolis: Casatrês, 2020, p. 119-152.

REIGOTA, Marcos. Educação Ambiental: a emergência de um campo científico. Perspectiva, v. 30, n. 2, p. 499-520, 2012.

REIGOTA, Marcos. Cidadania e educação ambiental. Psicologia \& Sociedade, v. 20, n. spe., p. 61-69, 2008a.

REIGOTA, Marcos. A educação ambiental para além dela mesma. Ambiente \& Educação, v. 13, n.1, p. 11-22, 2008b.

REIGOTA, Marcos. Ecologistas. Santa Cruz do Sul: EDUNISC, 1999a. 211 p.

REIGOTA, Marcos. A floresta e a escola: por uma educação ambiental pós-moderna. São Paulo: Cortez, 1999b. 167 p.

REIGOTA, Marcos; PRADO, Bárbara H. S. (Orgs.). Educação Ambiental: utopia e práxis. São Paulo: Cortez, 2008. 206 p.

ROLNIK, Suely. Cartografia sentimental: transformações contemporâneas do desejo. São Paulo: Estação Liberdade, 1989. 304 p.

SIBILIA, Paula. O show do eu. Rio de Janeiro: Nova Fronteira, 2008. 286 p.

SILVA, Tomaz Tadeu da. Teoria cultural e educação. Belo Horizonte: Autêntica, 2000. 128p. 
SILVA, Tomaz Tadeu da. Educação pós-crítica e formação docente. Cadernos de Educação, Pelotas, v. 8, p. 155-170, 1997.

SILVA, Luciano F.; CARVALHO, Luiz M. de. A temática ambiental e as diferentes compreensões dos professores de física em formação inicial. Ciência \& Educação, v. 18, n. 2, p. 369-383, 2012.

SILVA, Ana P.; SANTOS, Reginaldo P. Educação ambiental e sustentabilidade: é possível uma integração interdisciplinar entre o ensino básico e as universidades? Ciência \& Educação, v. 25, n. 3, p. 803-814, 2019.

SIQUELLI, Sônia. Revisão ética de projetos de pesquisa: aspectos normativos. In: Anped. Comissão de Ética. (Org.). Ética e pesquisa em Educação - v. 1. Rio de Janeiro: Anped, 2019, p. 30-35.

SOUZA, Elizeu Clementino de. Diálogos cruzados sobre pesquisa (auto)biográfica: análise compreensiva-interpretativa e política de sentido. Educação, v. 39, n.1, p. 39-50, 2014.

TAYLOR, Peter C.; MEDINA, Milton N. Teaching and learning transformative research: complexity, challenge and change. TAYLOR, Peter C.; LUITEL, Bal C. (Orgs.). Research as transformative learning for sustainable futures: glocal voices and visions. London: Brill, 2019, p. 39-57. 